\title{
IMPROVING BALANCE STABILITY THROUGH APPLICATION OF TRAINING PROGRAM IN STRESSFUL CONDITIONS VIA VIRTUAL REALITY GLASSES AND GLASSES SIMULATING ALCOHOL USE
}

\author{
Vladimir Angelov \\ National Sports Academy "Vassil Levski"
}

\begin{abstract}
The aim of this study was to investigate the effect of using difficult conditions in the balance training program through virtual reality glasses and glasses simulating alcohol consumption. According to the hypotheses of the study, the application of the balance training program with applying additional difficulty on the vestibular apparatus through technical means will lead to a greater training effect. The object of the study was the balance stability. The research was done among twenty-six Bulgarian students from the National Sports Academy. A pedagogical experiment was conducted to prove the hypothesis of the study. The testing session included two balance exercises. The collected data from the study were statistically processed with the variance analysis and t-criterion of Student. The results of the research were statistically significant and showed a greater increase in the parameters of the experimental group (FE: 33,3\%; $P=100 \%$; SE: 14,3\%; $P=99,9 \%$ ) than in those of the control group (FE: 14,7\%; $P=99,9 \%$; $S E: 8,3 \% ; P=99,9 \%)$. The analysis of the results justified the hypothesis of the research. The study found out that the usage of the balance training program that applies additional difficulty on the vestibular apparatus through virtual reality glasses and glasses simulating alcohol use leads to a better balance stability.
\end{abstract}

Key words: balance skills, vestibular apparatus, training conditions, stereoscopic glasses, glasses simulating alcohol consumption

\section{INTRODUCTION}

The rapid technological development in the world, in recent years, has significantly changed human life. It has affected all public spheres, including physical culture and sports. Athletes' balance abilities are known to be very important for the sports activities. Therefore, the main idea of this article was to use technology in the development of the balance training program. The author's attention was focused on the balance stability as very important motor quality. A lot of sports experts have worked on this problem. The literature review showed that most of those who are working in the field of balance performance are researchers and others are clinicians. Researchers' papers can be systematized into several groups: 1) studies of balance and posture control (Byl, 1992; Wade, Jones, 1997; Zernicke et al., 1982; Collins, DeLuca, 1993; Gurfinkel et al., 1965; MacKinnon, Winter, 1993; Okubo, et al., 1979; Roberts, 1976; Soames, Atha, 1980; Winter, 1987), 2) studies targeted at balance measurements (Bizzo et al., 1985; Black, Wall, 1982; Eng, Winter, 1993; Gagey, Weber, 2010 ; Geursen et al., 1976; Goldie et al., 1989; Hasan et al., 1990; Hasan et al., 1992; Jian et al., 1993; Kapteyn et al., 1983; Kirby et al., 1987; Koozekanani et al., 1980; Murray et al., 1967; Glave et al., 2016; Spaepen et al., 1977; Spaepen et al., 1979; Thompson et al., 2017), and 3) anatomical and physiological studies of balance maintenance (Nashner, 1977; Horak, Nashner, 1986; 
Winter et al., 1993). Clinicians' works are in two directions: investigations aimed to provide injury prevention and studies of the balance abilities of clinically ill people (Goldie et al., 1992; Skvortsov, 2000; Appiah-Dwomoh et al., 2016). Information about various methodological approaches for improvement of the balance performance is particularly important for the purposes of our study. However, we did not find any relevant studies in literature. The gaps in the literature served as motivation to realize the main idea of this paper and to complement the field of the research of balance performance. Of all sources we examined, the ones related to human postural control system and those with physiological focus can be defined as more relevant to our intentions. One of these articles reviews and analyzes the role of vision and spatial orientation in maintaining posture and balance (Wade, Jones, 1997). The key issues that relate to the development of postural control across the lifespan are discussed. Use of vision as a critical source of information that specifies spatial orientation in the environment is considered. In another paper a new conceptual and theoretical framework for studying the human postural control system is introduced (Collins, DeLuca, 1993). Mathematical techniques from statistical mechanics are developed and applied to the analysis and the interpretation of the stabilograms. Other authors used a whole-body inverted pendulum model to investigate the control of balance and posture in the frontal plane during human walking (MacKinnon, Winter, 1993). The model assessed the effects of net joint moments, joint accelerations and gravitational forces influencing the supporting foot and hip. Other sports experts examined how balance is affected and how it can be improved (Thompson et al., 2017). They consider that training and exercises that improve proprioception may improve one's postural capabilities, in particular, one's balance. They point out that inputs to the visual, somatosensory and vestibular systems are used for postural control, and that base-of-support impacts one's balance. In another article the authors studied the extent to which automatic postural actions in standing human subjects are organized by a limited repertoire of central motor programs (Horak, Nashner, 1986). Subjects stood on support surfaces of various lengths, which forced them to adopt different postural movement strategies to compensate for the same external perturbations. The aim of another study was to present firmer evidence that during stance functionally related postural muscles in the legs are activated according to fixed patterns (Nashner, 1977).

From the analysis of the anatomical and physiological studies of the balance maintenance and the studies of the balance and posture control, it can be concluded that they give knowledge that is applicable to the implementation of the planned balance program in this article. They outline the biomechanical aspects and the physiological mechanisms that characterize the performance of the balance exercises. The review of these literary sources, however, indicates a gap in the field of the methodology for developing individuals' balance abilities.

This paper was a continuation of the author's work on the issues of balance stability. The previous research emphasized on the means and methods for assessment of balance stability (Angelov et al., 2017; Albert et al., 2017). One of the preceding studies established the effect of the impact of various yogic exercises on participants' balance stability (Angelov et al., 2017). In this article we offer a classification of yogic asanas. Six groups of exercises are introduced: for muscle release, for balance, for strength, for stretching, in dynamic mode, and with combined impact. An 
influence with asanas from each group with the same duration and number of exercises was performed. After the execution of each group of asanas, a stabilographic measurement was performed. The analysis of the results shows that different groups of yogic exercises affect the practitioners' balance stability to a various extent. The article provides useful information of a methodical nature. The aim of another article was to create an algorithm for assessment and analysis of athletes' postural stability with the use of instrumentation methods (Angelov et al., 2017). This is the method of stabilogram analysis. It monitors the dynamics of Center of gravity (COG) by registration of the amplitude of the deviations and the frequency of the fluctuations of the COG during the execution of a balance task. An algorithm for working with the stabilograph platform was elaborated. A balance factor was created to compare the results of the measurements from different balance exercises. The next research paid attention to the balance abilities of the elite shooters in a standing position (Albert et al., 2017). A stabilograph platform was used again to assess the balance stability of the athletes.

A common feature of the mentioned papers is the method of stabilogram analysis for assessing the balance stability (Angelov et al., 2017; Albert et al., 2017). The review of these articles shows that their emphasis is on the methodology for measuring the indicators that allow assessment of balance stability. The present article is addressed to the field of the balance development methodology, as the abovementioned articles leave gaps in it. According to the hypotheses of the study, the application of the balance training program with applying additional difficulty on the vestibular apparatus through technical means will lead to a greater training effect and will increase athletes' balance stability.

It is important to note, that the known meth- odology developing the balance stability also uses difficult conditions. They are expressed in the use of small base of supports, movable supports, bosu balls, fitness balls, etc. In the reviewed literature no results of their application were found.

The aim of this study was to investigate the effect of the application of difficult conditions in the balance training program through stereoscopic glasses and glasses simulating alcohol consumption.

The purpose of the study was realized through the execution of certain tasks. A balance training program was elaborated. An audio-video that complicated the function of the vestibular apparatus by using stereoscopic glasses and glasses simulating alcohol consumption was provided. A pedagogical experiment was organized. The collected data were systematized, processed and analyzed.

\section{MATERIALS AND METHODS}

\section{Participants and training program}

The participants in the research were twenty-six Bulgarian students from the National Sports Academy. The age of the participants was $19-25$ years old ( $22 \pm 3$ years) - 10 women and 16 men. Each athlete had at least 5 years of sports experience in acrobatics, trampoline, and gymnastics. All participants from the experimental (EG) and the control (CG) group trained three times a week for three months, applying the same balance training program with duration of 20-30 minutes. The athletes from both groups performed with the same volume and intensity of the training load. The difference was that the athletes from the experimental group were put in difficult conditions - they used stereoscopic glasses and glasses simulating alcohol consumption during the performance of the training program.

The athletes fulfilled the following inclusion criteria: (1) a background of regular train- 
ing, (2) continuous training for the previous 3 months without any musculoskeletal injury, (3) absence of potential medical problems that could compromise the participation or performance in the study. The participants were informed in advance about the experimental design of the study.

We should point out that we used the following criteria when forming the experimental and control groups: (1) equal number of participants, (2) equal male/female ratio, (3) equal sport qualification, (4) equal ratio of the participants according to the sports specialization.

The training program included types of balance walking, static and dynamic balance exercises (Figure 1, 2).

The balance walking was performed on balance beams of different height. It included some different types of walking: on toes, on heels, on feet, and with moving straight, backward and with side-steps. The use of beams with different height had methodic importance connected with the athletes' fear barrier. On this basis, the mentioned types of walking first had to be performed on low beam and af- ter that on a higher one. The beams we used were four types. The low beams were $0.25 \mathrm{~m}$ (length $2.50 \mathrm{~m}$ ), $0.31 \mathrm{~m}$ (length $5 \mathrm{~m}$ ), and 0.34 $\mathrm{m}$ (length $5 \mathrm{~m}$ ) high. The highest beam was $0.95 \mathrm{~m}$ (length $5 \mathrm{~m}$ ). It is important to emphasize that the height was not based on the leg length or on the percentage of a fear index. The height of all used beams was factory-set and cannot be changed. The static balance exercises in the program consisted of variants of one leg standing and a handstand. The dynamic balance exercises included movements with hands, legs and trunk in standing position. Another part of the program was the execution of a backward somersault. The additional technical difficulty introduced in the EG was used as a stressful condition. The glasses simulating alcohol consumption blur the vision but do not occlude it, and for that reason were used for the types of balance walking and the acrobatic exercises performance (balance and dynamic). The stereoscopic VR glasses were used for the static and the dynamic exercises performed in a standing position, where the positions and the movements can be performed without visual control. $\mathbf{a}$

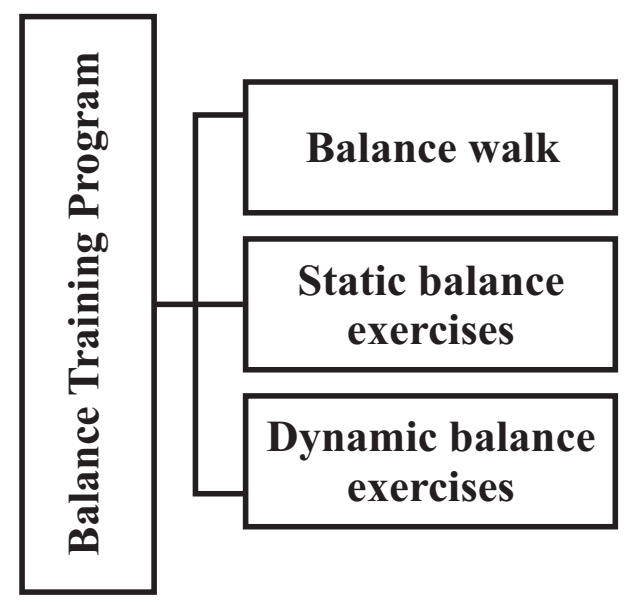

b

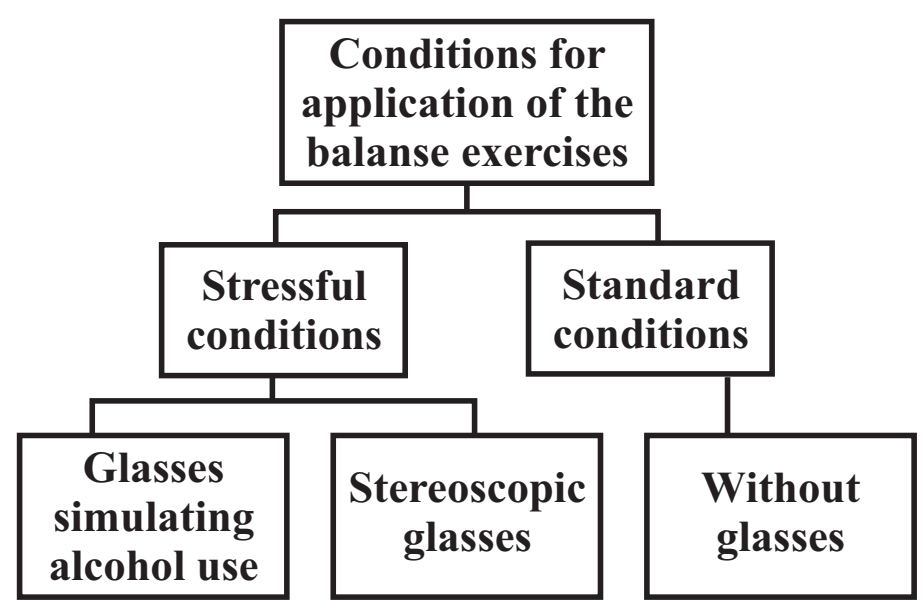

Figure $1(\mathbf{a}, \mathbf{b})$. Contents of the balance training program.

(a)-Components of the program; (b) -Different conditions for application of the program. 


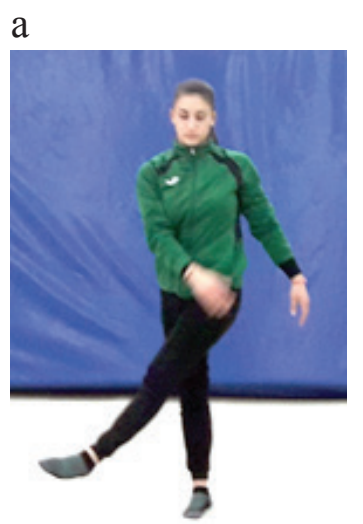

b

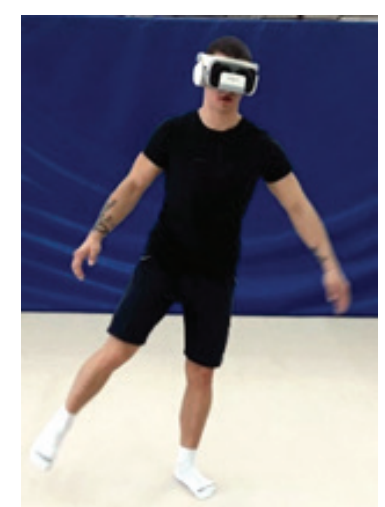

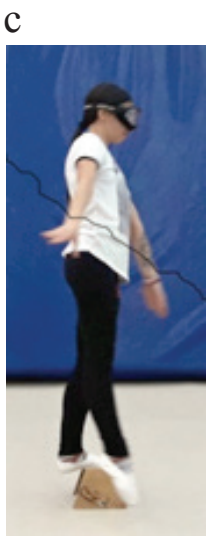

Figure 2 (a, b, c). Sample exercises from the balance training program of the $C G$ and $E G$. (a) - a dynamic exercise in standard conditions; (b) - a static exercise with stereoscopic glasses; (c) - a static exercise with glasses simulating alcohol use.

The stressful effect on the vestibular apparatus was accomplished with the help of two devises: glasses simulating alcohol consumption (Figure 3a) and VR glasses (Figure 3b).

The usage of the glasses simulating alcohol consumption led to blurred vision without excluding the visual control. This kind of glasses simulates 1.5\% alcohol use.

$3 \mathrm{D}$ Roller Coaster video was played on VR glasses. The roller coaster simulation was chosen on the base of the preliminary testing and because it makes the function of the vestibular apparatus difficult. Thus, the visual control during the impact was totally off. Stereoscopic glasses working with a smartphone were used. The device was a BOBO VR Z5 brand with autonomous headphones that allowed more concentrated audio impact. The video resolution of the smartphone was FHD and allowed for high-quality video.

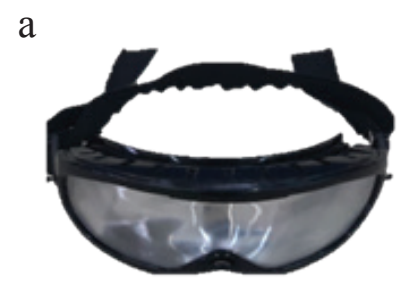

All participants were warmed up for 20-30 minutes before the beginning of the balance training program. The athletes performed a standard warm-up consisting of 5-7 min of running exercises followed by $10-15 \mathrm{~min}$ of dynamic gymnastic exercises and 5-8 min of static stretching.

\section{Experimental Design and Equipment}

The research consisted of three stages. During the first stage we defined the concept, organized the study and executed the initial testing session. In the second stage, the pedagogical experiment was conducted. The third stage contained the final testing session, the data processing and the analysis of the results.

The following scientific methods were used to carry out the study: sports-pedagogical testing, expert evaluation, pedagogical observation, pedagogical experiment and statistical methods.

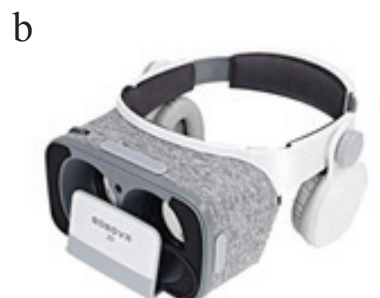

Figure 3 (a, b). Technical devises used to make the function of the vestibular system difficult. (a) - Glasses simulating alcohol consumption; (b) - VR glasses. 


\section{Test Description}

The assessment of the balance stability was realized with the help of two tests. The first test included a dynamic and static part. The session began with a performance of five forward rolls one after another followed by one leg standing (Figure 4a). During the balance holding, the supported leg had to be absolutely straight like the raised leg that should be at least on a horizontal level. The aim of

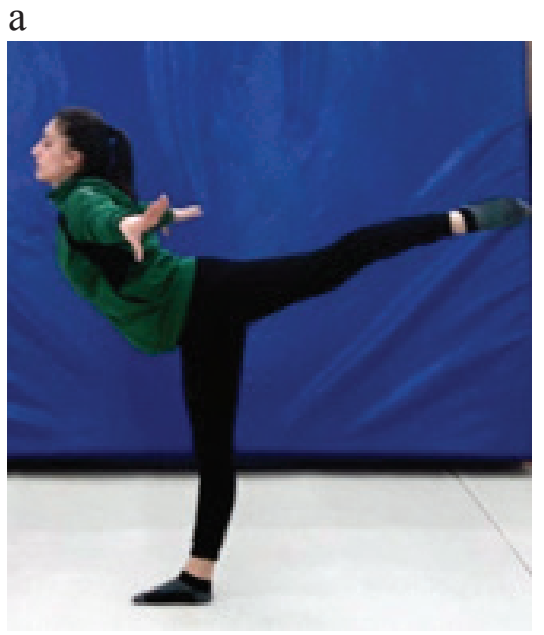

the test was to hold the balance position for maximum duration. The second test consisted of one leg standing above the cross-bar small base of support. The purpose was like in the previous test - balancing in a static position with stretched supported leg for maximum duration (Figure 4b). The selected two tests fulfilled the following criteria: standardization, information, reliability, validity and objectivity.

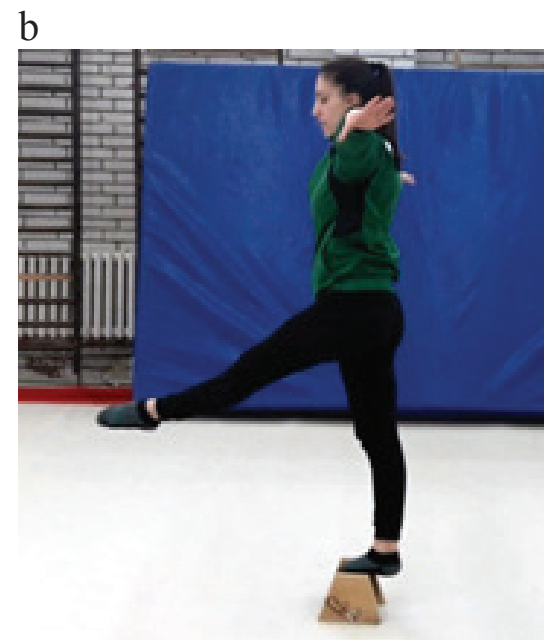

Figure 4 (a, b). The balance positions of the first and the second test.

\section{Measurement Procedure}

A pedagogical experiment was conducted to prove the hypothesis of the study. Two measurements were made to establish the participants' balance abilities. The first measurement was made before the beginning of the pedagogical experiment, and the second - after it was completed. The testing session consisted of the abovementioned two balance exercises. The measurement was realized with the help of a stop watch. The unit of measurement was seconds. Each measurement began when the athlete occupied the balance position and was canceled in case of balance loss or violation of the test rules. The test rules are mainly related to maintaining a correct body position during the performance of the two testing exercises.
During the balance standing the supporting leg should be stretched, the raised leg must be straight and at least horizontally (in the first test), it is not allowed to take steps during the performance and to touch the floor with hands.

Age, gender, weight, height, number of training years, training days per week, training minutes per session and the type of sport practiced by the participants were recorded. Oral instructions as well as a demonstration of how the test should be performed were given to the athletes.

\section{Data and Statistical Analysis}

A case report with relevant data for analysis was handwritten. From the data, a computation was performed. The collected data from the study were statistically processed with the 
computer program SPSS Statistics 17.0. The data were first descriptively analyzed (mean \pm standard deviation), then an independent t-tests and paired t-tests for the normal data distribution was done. Shapiro-Wilk (SW) test was used to determine normality of data distribution. To define the statistical significance of the differences, the confidence interval was used $(\mathrm{P}>95 \%)$.

\section{RESULTS}

Assessment of balance stability via two testing exercises.

Here the data from the testing session are displayed. Table 1 summarizes the mean values (SD) for each test performed by the experimental and control group during all stages of the pedagogical experiment. Figure 5 (a, b) shows the same results through two bar graphs. It allows a more efficient comparison of balance holding continuation.

Table 1. Results of the testing sessions during the pedagogical experiment.

\begin{tabular}{llll}
$\begin{array}{l}\text { Phases of the } \\
\text { pedagogical experiment }\end{array}$ & Testing exercises & Experimental group & Control group \\
\hline Initial phase & $\begin{array}{l}\text { First exercise } \\
\text { Second exercise }\end{array}$ & $36.0( \pm 7.3)$ & $34.0( \pm 9.8)$ \\
& & & $25.3( \pm 4.1)$ \\
Final phase & $\begin{array}{l}\text { First exercise } \\
\text { Second exercise }\end{array}$ & $48.0( \pm 9.8)$ & $39.0( \pm 7.3)$ \\
&
\end{tabular}

Note: Values are mean ( $\pm S D)$.

Table 1 and Figure 5 (a) display the results from the first testing session. The two testing groups had similar achievements. The experimental group demonstrated a better initial level of balance stability after the two testing exercises. A bigger difference in the results was found in the second test. This fact can be explained by the nature of the tests used and the sports specialization of the participants. First, the two tests have a great informative value about the static balance. The first test includes dynamic and static part. The dynamic part makes the function of the vestibular apparatus difficult. The second test definitely requires better static balance skills. Second, in the method section the criteria for the formation of the two groups are specified. On this basis, the participants are in equal conditions. The only difference in the composition of the EG and the $\mathrm{CG}$ according to the sport practiced is the violation of ratio between the number of the athletes. The number of trampoline practitioners is bigger in the $\mathrm{CG}$. The three gymnastics sports (artistic gymnastics, sports acrobatics and trampoline) influence the functions of the vestibular system. Trampoline practitioners develop dynamic balance skills rather than static skills. Gymnastics and acrobatics improve the two types of balance. These peculiarities of the balance tests and the motor activity explain the bigger difference in the results from the second test. The group with more trampoline practitioners showed lower values of the results. 
FIRST STUDY

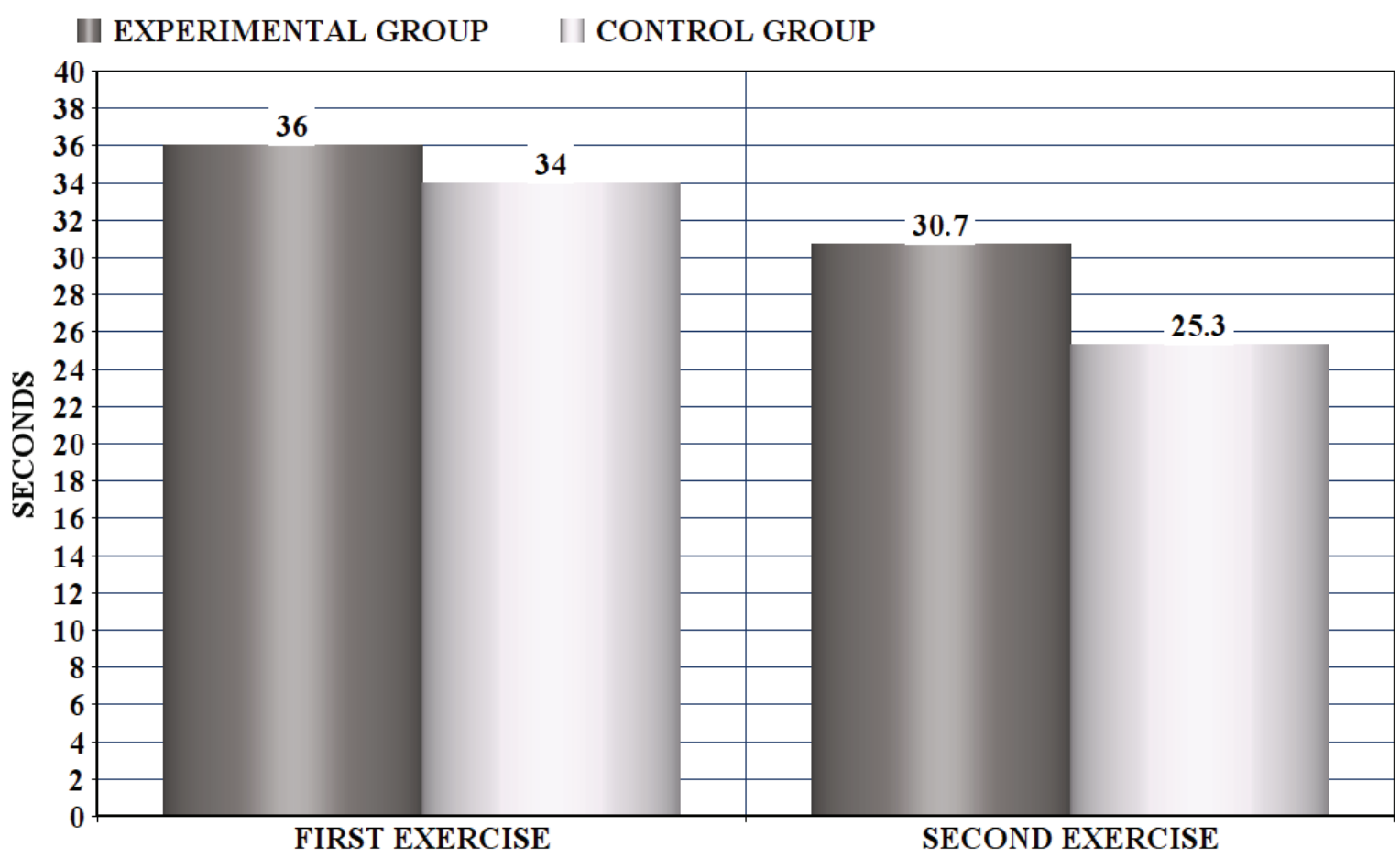

SECOND STUDY

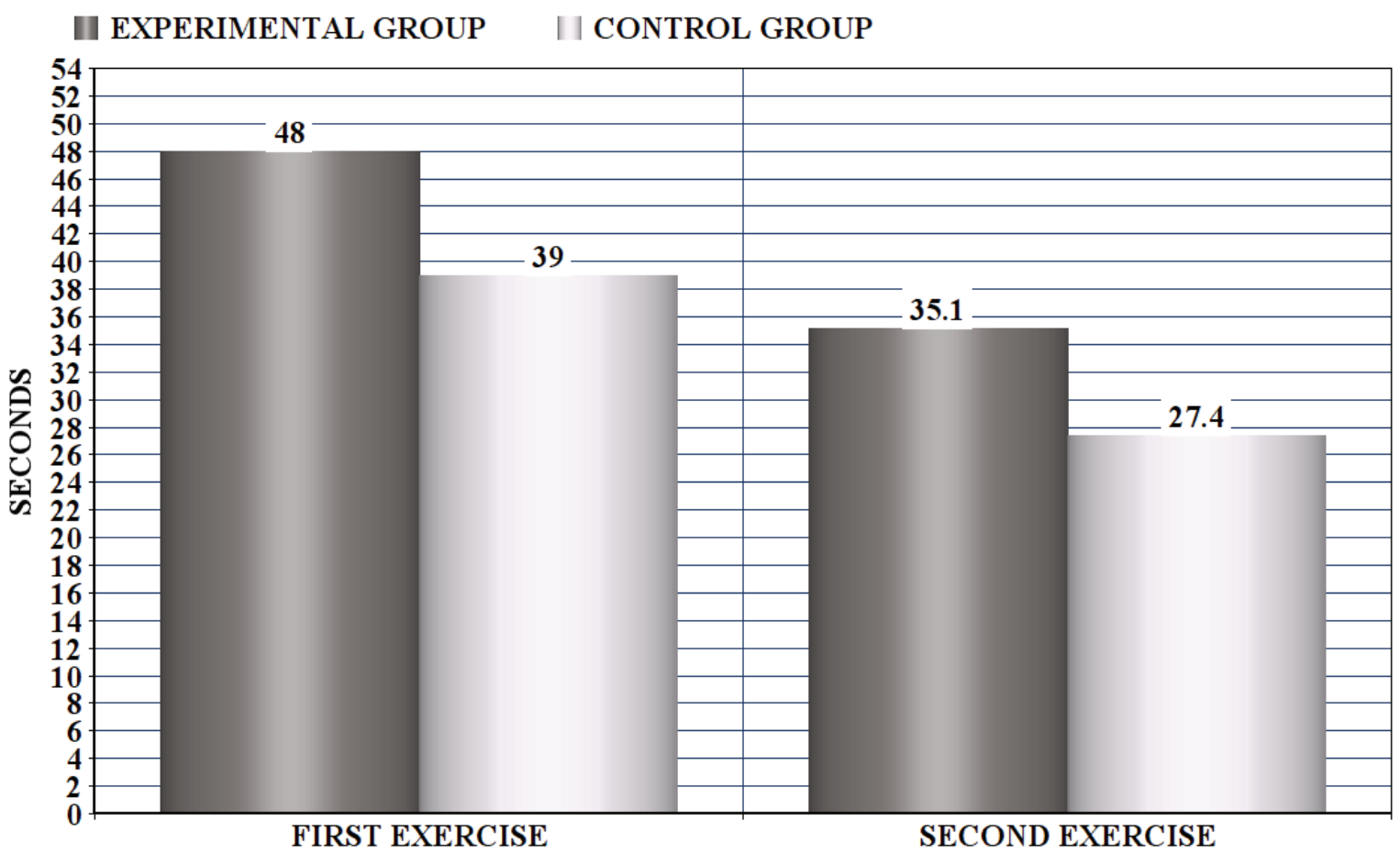

Figure 5 (a, b). Mean values of the results from the testing sessions during the pedagogical experiment. 
Table 1 and Figure 5 (b) summarize the data obtained from the second testing session. On the basis of the results displayed on the bar graph, it is obvious that the participants in the EG have a greater increase in the balance stability level. The achievements of this group in both tests prove it.

\section{Comparisons of the collected data.}

Table 2 and Figure 6 contain information about the five comparisons of the differences and the growths and their statistical significance, which aims to prove more convincingly the hypothesis of the study. They present the values of the absolute $(d)$ and relative $(d \%)$ growth of the results of the two groups (1st and 2nd comparisons), the differences of the results between the EG and the $\mathrm{CG}$ in the two phases of the experiment (3rd and 4th comparison) and the difference of the growth of the two groups (5th comparison). The percentage values of the differences only in the first and the second comparison were calculated.

The bar graph in Figure 7 shows the growth of the results in the experimental and control group after the calculation of the new variables.

Table 2. Results from the comparisons of the differences in the variables and their Statistical significance during the two phases of the pedagogical experiments.

\begin{tabular}{llllc}
\hline Comparisons & Testing exercises & d (s) & d c & P c \\
\hline $\begin{array}{l}\text { First comparison - } \\
\text { growth in the EG }\end{array}$ & First exercise & 12 & 33,3 & 100 \\
$\begin{array}{ll}\text { Second comparison - } \\
\text { growth in the CG }\end{array}$ & Second exercise & 4,4 & 14,3 & 99,9 \\
$\begin{array}{l}\text { Third comparison - } \\
\text { differences between }\end{array}$ & Second exercise & 2,1 & 8,3 & 99,9 \\
$\begin{array}{l}\text { EG and CG in 1st phase } \\
\begin{array}{l}\text { Fourth comparison - } \\
\text { differences between }\end{array}\end{array}$ & First exercise & 2 & - & 40,6 \\
$\begin{array}{l}\text { EG and CG in 2nd phase } \\
\text { Fifth comparison - }\end{array}$ & First Exercise & 9 & - & 97,6 \\
$\begin{array}{l}\text { differences between } \\
\text { the growth of EG and CG }\end{array}$ & Second exercise & 7,7 & - & 99,5 \\
& First Exercise & 7 & - & 99,9 \\
\hline
\end{tabular}

Note: Values are d (s) -absolute growth; d\% - relative growth; Pc/ - confidence interval.

As we mentioned, five comparisons were made to prove the hypothesis of the study (Table 2, Figure 5, Figure 6, Figure 7).

The first comparison informed about the growth of the results of the experimental group as a result of the new impact through the application of balance training in stressful conditions. The results from the two tests are sta- 
tistically significant (P1=100\%, P2=99.9\%). The absolute growth (d) in the first and second tests is respectively $12 \mathrm{~s}$ and $4.4 \mathrm{~s}$. The relative growth (d\%) is $33.3 \%$ and $14.3 \%$. A better increase was found in the first test compared to the second. This finding can be explained by the peculiarities of the first test and the nature of the new impact. As we mentioned, the first part of the first test makes the function of the vestibular apparatus difficult because of the dynamic exercise. The new impact with the help of VR glasses and glasses simulating alcohol use has a similar effect on the vestibular system. Thus, the commented similarity can be defined as a reason for the greater increase in the results of the EG in the first test.

The second comparison determined the increase in the results of the control group during the pedagogical experiment. This comparison shows the effect of the training program application under standard conditions. The results from the two tests are statistically significant (P1=99.9\%, P2=99.9\%). The absolute growth (d) in the first and second tests is respectively $5 \mathrm{~s}$ and $2.1 \mathrm{~s}$. The relative growth $(\mathrm{d} \%)$ is $14.7 \%$ and $8.3 \%$. Here, there was also a greater increase in the first test compared to the second one but the difference between the results was not big. However, the better performance of the athletes of this group in the first test can be explained with the fact that the balance position of the first test is an exercise of the participants' standard training.

The first and second comparisons allowed us to compare the effect of the training program made up of the same exercises but performed under different conditions. On this ba- sis we could draw a conclusion that the greater results of the experimental group were due to the new impact.

The third comparison gave an idea of the statistical significance of the differences in the results between the experimental and the control groups during the first phase of the study $(\mathrm{P} 1=40.6 \%, \mathrm{P} 2=95.1 \%)$. There was a statistical insignificance in the first exercise. The difference of the results in the first and second tests is respectively $2 \mathrm{~s}$ and $5.4 \mathrm{~s}$. This comparison aimed to show whether the further processing of the results was comparable. The experiment could turn out to be meaningless provided that we established considerable differences between the results of the two groups during the first testing session. The lack of similarity in the participants' initial level was not a good prerequisite for the credibility of the hypothesis of the study. Nevertheless, there was a statistical insignificance in the first exercise as well as a qualitative similarity between the results in both groups. Therefore, the further assessment of the results was possible.

The fourth comparison fixed the statistical significance of the differences in the results between the EG and $\mathrm{CG}$ during the second phase of the study $(\mathrm{P} 1=97.6 \%, \mathrm{P} 2=99.5 \%)$. The difference of the results in the first and second tests is respectively $9 \mathrm{~s}$ and $7.7 \mathrm{~s}$. The observed differences in both groups allowed us to draw conclusions about the effect of the standard and the new impacts. The results from the second phase of the study were in favor of the experimental group. 


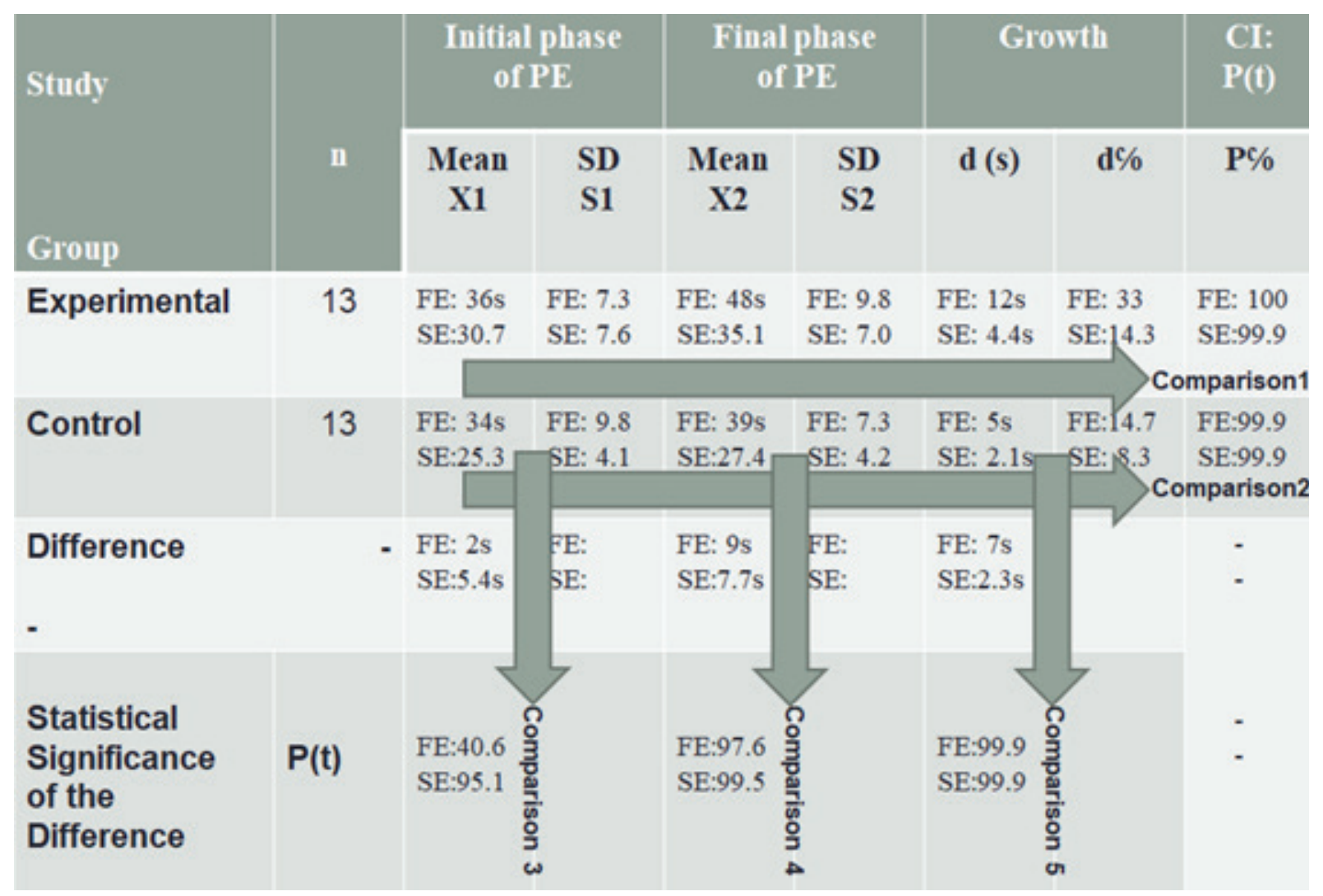

Figure 6. Comparisons of the results during the pedagogical experiment, proving the hypothesis of the study.

Note: FE - first exercise; SE - second exercise; CI (Pc) - confidence interval; $d(s)$ - absolute growth; d\% - relative growth;

The fifth comparison (Figure 7) confronted the growth of the EG and CG and found their statistical significance. This is the most important comparison for proving the hypothesis of the study. For this purpose, new variables for the increase in the results were calculated in each of the tests. The comparison showed that results were statistically significant (P1=99.9\%, P2=99.9\%). The difference of the growths in the first and second tests is respectively $7 \mathrm{~s}$ and $2.3 \mathrm{~s}$ in favor of the EG. The analysis of the data showed a few times greater increase in the first test compared to the second. We consider that the main cause of this is rooted in the big similarity between the new impact and the nature of the first test. In both cases the balance positions were performed after the vestibular apparatus had been exposed to stress. 


\section{E EXPERIMENTAL GROUP $=$ CONTROL GROUP}

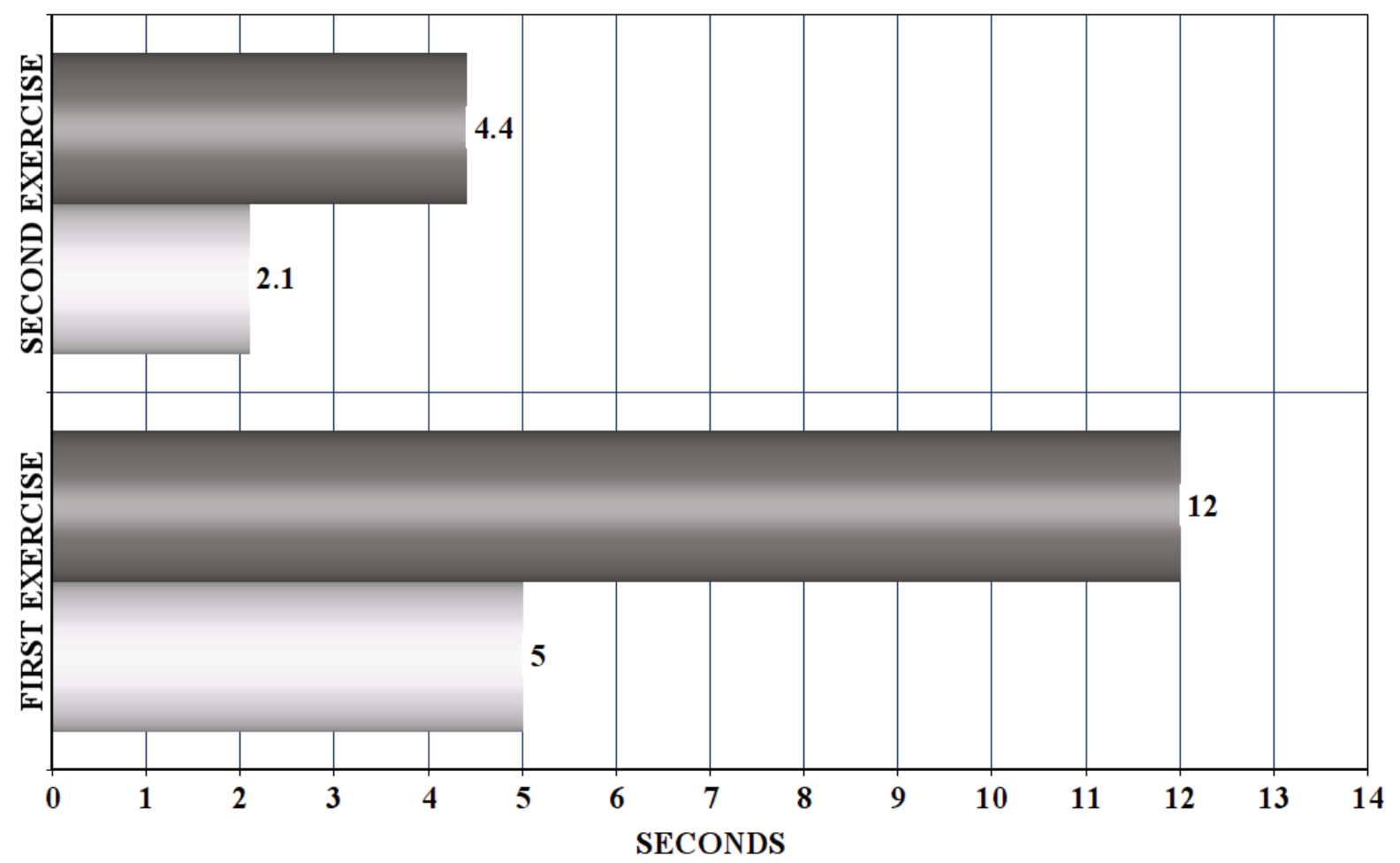

Figure 7. Growth in the results after the calculation of the new variables.

\section{DISCUSSION}

The reviewed literary sources make it clear that the emphasis in them is on the assessment of the balance abilities of the subjects. No information similar to the basic concept of this work was found. The use of difficult conditions in the balance development methodology is not a new idea. The balance exercises performed on fitness balls, bosu balls, small base of supports, movable supports, etc. take place in the training programs for balance improvement. The training devices we used for balance development can be defined as difficult conditions. It is important to note, that we did not find any information about balance research with the use of such apparatuses.

On this basis, what is new in this work? This is an attempt to apply an additional impact on the vestibular apparatus with glasses simulating alcohol use and 3D Roller Coaster video played on VR glasses as a difficult condition. Why was 3D Roller Coaster video used? The main reason for the choice of a roller coaster simulation was a preliminary testing. The application of $3 \mathrm{D}$ roller coaster video through VR glasses even in a usual standing position makes maintaining one's balance difficult. This simulation allowed us to implement the idea of our research. The execution of the balance tasks in such conditions by the participants of the EG is a novel approach. In further research, different types of $3 \mathrm{D}$ video simulations can be used to make the function of the vestibular apparatus difficult and a simulation of balance tasks performance with open and closed eyes can be determined.

The literature review showed that in several studies (Hasan, Robin, Shiavi, 1992 and Okubo, Watanabe, Takeya, Baron, 1979) such an approach was used. These articles can be considered as more relevant to the essence of the proposed training methodology in this pa- 
per. The difference was that open and closed eyes were used to perform tests for balance stability assessment. The use of the glasses simulating alcohol consumption can be compared with the behavior of the subjects performing balance exercises with open eyes. The use of VR glasses brings athletes closer to the conditions of balance exercises performed with closed eyes. In this study, the effect of open/closed eyes during performing balance tasks is achieved by using technical devices. This is a new point because balancing with and without visual control is used as an impact, whereas in the cited articles it is part of the balance assessment tests.

The main idea of this study was to compare the training effect between the standard balance training program and the program with additional difficult conditions for vestibular apparatus with stereoscopic glasses (Figure 1b) and glasses simulating alcohol use (Figure 1a).

The collected data allows to make meaningful comparisons between participants of the experimental and control group and on this basis to form general conclusions about the effects of balance training program performed under the two types of conditions - normal and difficult.

We observed an increase in balance stability of the participants in the EG. They had greater difficulty keeping their balance while executing the exercises from the training program. The athletes in this group made more mistakes during the performance of the balance tasks. The reason for this was the embarrassing function of the vestibular apparatus via VR glasses and glasses simulating alcohol consumption. In conclusion, the two groups EG and CG performed the balance tasks during the pedagogical experiment on different technical level. It was considered to be methodically appropriate not to set a threshold of errors in regard to the performance of the balance program. It is normal that the execution of equal exercises but in different conditions be with different quality. That's why only the results from the testing session were compared. This study used sports pedagogical tests for assessment of the balance stability as opposed to our previous articles which used more qualitative-type assessments (Angelov et al., 2017; Albert et al., 2017).

The analysis of the results shows that the application of these technical devices in the balance training program leads to better results concerning athletes' balance stability. The study found that the participants in the experimental group had a higher increase in the results from both test exercises (Figure 7).

The relation between the gender and the age of the participants was not investigated. The author intends to expand the research scope on the above-mentioned criteria and to look for a correlation between them in further studies.

Another possibility to extend the research area is to compare the results of the application of various types of difficult conditions during the balance training program. For this purpose, a new experiment has to be carried out in which one group performs the balance tasks using the technical devices discussed in this article, and the other group performs the balance program using a small base of support, a movable support, a fitness ball, and a bosu ball.

This research area can be extended in future studies focusing on including a greater number of participants of different ages who are representatives of different sports and have different qualifications. I believe that this kind of research will be very useful to teenagers because at this age the balance stability is developing at its highest pace. An additional contribution to the improvement of the new 
methodology will be the conduct of clinical trials.

Another opportunity for investigation of the effect of the application of the virtual reality on the balance training will be the use of the method of the stabilogram analysis for assessment of balance stability. It will help to determine the Center of gravity deviation and the frequency fluctuation during the balance exercises performance in both examined conditions (normal and stressful with the help of VR). That will provide additional information about the outer and inner sides of the movements during the balancing process in standard and stressful conditions with the help of virtual reality.

This study is limited by age, sports qualification, sports specialization, and the number of the participants. Secondly, the analysis of the results can be considered as a limitation to some extent. The collected data from the study of the additional impact with the help of glasses simulating alcohol consumption and VR glasses were analyzed on their own, without searching for any relation between them. Naturally, this circumstance is due to the design and organization of the research.

According to the reviewed literature in this article and in my opinion, a conclusion can be made that for successful elaboration and application of any balance methodology, we should be in line with the biomechanical regularities and physiological mechanisms during the performance of the balance tasks.

\section{CONCLUSIONS}

The analysis of the results justified the hypothesis of the research. The study found that the use of the balance training program that applies additional difficulty to the vestibular apparatus through technical means leads to better results in balance stability. The application of glasses simulating alcohol con- sumption and VR glasses can successfully be applied in balance training as an alternative to the other types of difficult conditions discussed in this study. It is important to emphasize that the proven effect of the new impact does not make it a basic method in the training process. We recommend that stressful conditions with technical means should be used as an additional tool in balance training and as a possibility to introduce some variety in the training process.

\section{REFERENCES}

Albert, E., Tishinov, O., Angelov, V. (2017). Improving of the balance stability in standing position with highly qualified athletes. Sports and Science, pp. 2, 75.

Angelov, V., Tishinov, O., Albert, E. (2017). Study of the Balance Stability of Yoga Exercises Practitioners. Journal of Applied Sports Sciences, 1, pp.13-20.

Angelov, V., Tishinov, O., Gotova, J., Albert, E., Stoimenov, E., Hristov, V. (2017). Method of the Stabilogram Analysis for Reseach of the Balance Stability in Sport. Book of Abstracts of 22nd Annual Congress of the European College of Sports Science, pp. 592.

Appiah-Dwomoh, E.K.,Müller, S., Hadzic, M., Maye, F. (2016). Star Excursion Balance Test in Young Athletes with Back Pain. Sports, 4, pp. 44.

Bizzo, G., Guillet, M., Patat, A., Gagey, P.M. (1985). Specifications for building a vertical force platform designed for clinical stabilometry. Medical \& biological engineering \& computing, 23, pp. 474-476.

Black, F.O., Wall, C. 3rd, Rockette, H.E., Kitch, R. (1982). Normal subject postural sway during the Romberg test. American journal of otolaryngology. 3, pp. 309-318.

Byl, N.N. (1992). Spatial orientation to gravity and implications for balance training. Orthopaedic Physical Therapy Clinics of 
North America. 1, pp. 207-242.

Collins, J.J., DeLuca, C.J. (1993). Openloop and closed-loop control of posture: A random-walk analysis centre-of-pressure trajectories. Experimental Brain Research. 95, pp. 308-318.

Eng, J.J, Winter, D.A. (1993). Estimations of the horizontal displacement of the total body centre of mass: considerations during standing activities. Gait and Posture. 1, pp. 141-144.

Gagey P.M., Weber, B. (2010). Posturologie. Regulation et dereglements de la station debout, 3rd ed., Masson: Paris, France, pp. 145.

Geursen, J.B., Altena, D., Massen, C.H., Verduin, M. (1976). A model of standing man for the description of his dynamic behaviour. Agressologie. 17, pp. 63-69.

Glave, A.P., Didier, J.J., Weatherwax, J., Browning, S.J., Fiaud, V. (2016). Testing Postural Stability: Are the Star Excursion Balance Test and Biodex Balance System Limits of Stability Tests Consistent? Gait and Posture, 43, pp. 225-227.

Goldie, P.A., Evans, O.M., Bach, T.M. (1992). Steadiness in one-legged stance: development of a reliable force platform testing procedure. Archives of Physical Medicine and Rehabilitation. 73, pp. 348-354.

Goldie, P.A., Bach, T.M., Evans, O.M. (1989). Force platform measures for evaluating postural control: reliability and validity. Archives of physical medicine and rehabilitation. 70, pp. 510-517.

Gurfinkel, V.S., Kots, Y.M., Shik, M.L. (1965). Regulation of human posture. Nauka: Moscow, Russia.

Hasan, S.S., Lichtenstein, M.J., Shiavi, R.G. (1990). Effect of loss of balance on biomechanics platform measures of sway: influence of stance and a method of adjustment. Journal of biomechanics. 23, pp. 783-789.
Hasan, S.S., Robin, D.W., Shiavi, R.G. (1992). Drug and postural sway. IEEE Engineering in Medicine and Biology Magazine. 11, pp. 35-41.

Horak, F.B., Nashner, L.M. (1986). Central programming of postural movements: adaptation to altered support surface configurations. Journal of Neurophysiology. 55, pp. 1369-1381.

Kapteyn, T.S., Bles, W., Njiokiktjien, Ch.J. et al. (1983). Standardization in platform stabilometry being a part of posturography. Agressologie, 7, 24, pp. 321-326.

Jian, Y., Winter, D.A., Ishac, M.G., Gilchrist, L. (1993). Trajectory of the body COG and COP during initiation and termination of gait. Gait \& Posture. 1, pp. 9-22.

Spaepen, A.J., VranKen, M., Williams, E.J. (1977). Comparison of the movements of the centre of gravity and center of pressure in stabilometric studies. Agressologie. 18, pp.109-113.

Kirby, R.L., Price, N.A., MacLeod, D.A. (1987). The influence of foot position on standing balance. Journal of biomechanics. 20, pp. 423-427.

Koozekanani, S.H., Stockwell, C.W., McGhee, B.B., Firoozmand, F. (1980). On the role of dynamic models in quantitative posturography. IEEE Transactions on Biomedical Engineering. BME-27, pp. 605-609.

MacKinnon, C.D., Winter, D.A. (1993). Control of whole-body balance and posture in the frontal plane during walking. Journal of biomechanics. 26, pp. 633-644.

Murray, M.P., Seireg, A., Scholz, R.C. (1967). Center of gravity, center of pressure and supportive forces during human activities. Journal of Applied Physiology. 23, pp. 831838.

Nashner, L.M. (1977). Fixed patterns of rapid postural responses among leg muscles during stance. Experimental Brain Research. 
30, pp. 13-24.

Okubo, J., Watanabe, I., Takeya, T., Baron, J.B. (1979). Influence of foot position and visual field condition in the examination of equilibrium function and sway of center of gravity in normal persons. Agressologie. 20, pp. 127132.

Roberts, T.D.W., Stenhouse, G. (1976). The nature of postural sway. Agressologie. 17A, pp. 11-14.

Skvortsov, D.V. (2000). Clinical analysis of movements. Stabilometry. AOZT "Antidor": Moskow, Russia.

Soames, R.W., Atha, J. (1980). The validity of physique-based inverted pendulum models of postural sway behaviour. Annals of Human Biology. 7, pp. 145-153.

Spaepen, A.J., Peeraer, L., Willems, E.J. (1979). Center of gravity and center of pressure in stabilometric studies. Agressologie. 20, pp. 117-118.

Thompson, L.A., Badache, M., Cale, S.,
Behera, L., Zhang, N. (2017). Balance Performance as Observed by Center-of-Pressure Parameter Characteristics in Male Soccer Athletes and Non-Athletes. Sports, 5, pp. 86.

Wade, M.G., Jones, G. (1997). The Role of Vision and Spatial Orientation in the Maintenance of Posture. Physical Therapy, 77, pp. 6.

Winter, D.A. (1987). Sagittal plane balance and posture in human walking. IEEE engineering in medicine and biology magazine. 6 , pp. 8-11.

Winter, D.A., Prince, F., Stergiou, P., Powell, C. (1993). Mediallateral and anterior-posterior motor responses associated with centre of pressure changes in quiet standing. Neuroscience Research Communications. 12, pp. 141-148.

Zernicke, R.F., Gregor, R.J., Crafty, B.J. (1982). Balance and visual proprioception in children. Human Movement Science. 8, pp. 1-13.

\section{Corresponding author:}

Vladimir Angelov

Department of ,Gymnastics“" National Sports Academy "Vassil Levski" Studentski grad, 21, Acad. Stefan Mladenov str. Sofia 1700, Bulgaria E-mail: angelov.v1@gmail.com 